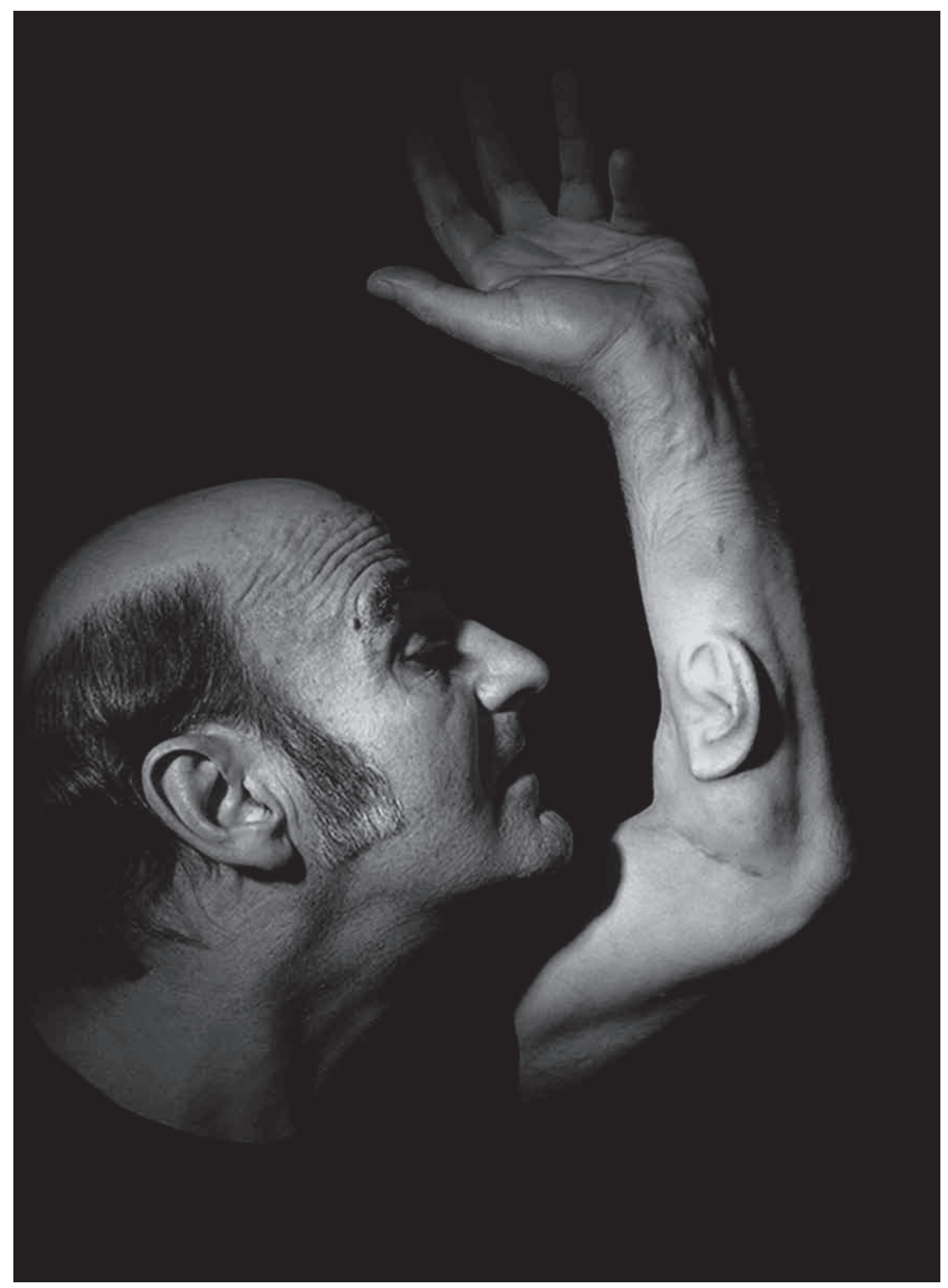


ARS Carlos Augusto Moreira da Nóbrega [Guto Nóbrega]*

ano 11

n. 22

\section{Bot_anic. Acoplamentos estruturais entre plantas, homens e máquinas.}

palavras-chave: arte, Bot_anic, planta, robô, híbrido.

keywords: art, Bot_anic, plant, robot, hybrid.

Eduardo Kac, Stelarc: ear on arm, imagem de Nina Sellars impressão fotográfica.

* Escola de Belas Artes - Universidade

Federal do Rio de Janeiro (UFRJ).
Bot_anic resulta do processo de invenção de um sistema planta/robô que dá continuidade às investigações sobre híbridos com base no entrecruzamento de organismos naturais e artificiais no contexto da arte. No presente artigo tomaremos por referência este projeto para refletir sobre o processo de criação de autômatos, a geração de comportamento emergente por simplicidade e sobre as ligações sensíveis da experiência artística interfaceada pelo uso de tecnologias.

Bot_anic results from the process of inventing a plant/robot system, which follows the investigation about hybrids based on the intercrossing of natural and artificial organisms in the context of art. At the present paper we will take as reference this project to think about the process of creating automatons, the generation of emergent behaviour by simplicity and about the sensible liaisons of the artistic experiences interfaced by the use of technologies. 


\section{Introdução}

Bot_anic resulta da invenção de um híbrido, planta/máquina, que investiga os processos com base no entrecruzamento de organismos naturais e artificiais como arte. A motivação para o uso de plantas na criação de processos artísticos, em especial, na produção de trabalhos que operam na zona de interseção entre a ciência e a tecnologia ${ }^{1}$, vem da necessidade de problematizar os processos de interação entre autor, obra e observador. Partimos do pressuposto de que tal tríade articula-se na forma de uma matriz $^{2}$, na qual um dado jogo ocorre com vistas à emergência de uma experiência sensível. Acreditamos estrategicamente no uso de plantas, assim como outros possíveis sistemas orgânicos vivos, como potenciais agregadores de uma sensibilidade conectiva aos processos tecnológicos, uma conectividade inerente aos organismos de natureza viva que parecem ter seus modelos espelhados ${ }^{3}$ nos sistemas artificiais que nos reorientam no mundo contemporâneo. Problematizar os processos interativos significa, em primeira instância, superar o constrangimento da cadeia de causa e efeito inerente aos dispositivos programados para a experiência sensível; abrir o trabalho artístico efetivamente aos processos emergentes, dialogar com o acaso, pensar e gerar a obra considerando, sobretudo, seu caráter sistêmico/conectivo. Acreditamos que as propriedades inerentes aos organismos vivos e seus comportamentos são porta de acesso à zona sutil entre a dureza redutiva das máquinas e a umidade complexa dos seres viventes.

É nesse sentido que apresentamos o trabalho Bot_anic, um composto planta/sistema robótico, que estabelece com o observador um jogo sensível quando o mesmo interage com a planta através de sua respiração. A partir da apresentação desse trabalho abordaremos questões sobre a criação de autômatos no contexto da arte, assim como investigaremos a invenção de sistemas híbridos sob a perspectiva de uma arquitetura poética, ecossistêmica e em rede.

\section{Bot_anic}

Bot_anic (fig. 1) deriva e é inspirado no trabalho Breathing (2008), do presente autor, que deu origem aos métodos e procedimentos que vêm sendo aplicados em nossas mais recentes criações. Tais projetos investem no uso de plantas como agentes sensíveis para construção de uma experiência artística. Assim como em Ephemera (2008), Equilibrium (2008) e
GUTO NÓBREGA

Bot_anic.

1. 0 termo tecnologia

é compreendido aqui

no sentido de um

conjunto de técnicas,

conhecimentos e

métodos usados com

objetivo de resolver um

certo problema. Não se

trata aqui de uma técnica

singular, mas de um

processo sistêmico

e agregador

de inteligência.

2. Cf. ASCOTT, Roy.

Behaviourist art and cybernetic vision (1966-

67). In: ASCOTT, Roy e

SHANKEN, Edward A.

Roy Ascott. Telematic

embrace: visionary the-

ories of art, technology,

and consciousness.

London: University of

California Press, 2003.

3. Aqui nos referimos ao fato de que o uso de tecnologia espelhar, através de seus canais interativos, modelos da natureza e refleti-los de volta para nós de maneira transformada. Ver ROKEBY, David. Transforming mirrors: subjectivity and control in interactive media (1996). Disponível em: «http://homepage. mac.com/davidrokeby/ mirrors.html». Acesso em: agosto de 2013. 
Breathing (2008) (ver fig. 2), Bot_anic estabelece sua poética a partir de uma relação afectiva ${ }^{4}$ entre o observador, a máquina e o organismo vegetal

4. Aqui o termo afectivo é empregado para diferenciar-se de afeto, se aproximando da forma como afecto é empregado por DELEUZE, Gilles e GUATTARI, Félix. 0 que é a filosofia? São Paulo: Editora 34, 1997.

5. A programação de Bot_anic foi construída com base em estados

de máquina. Uma série de estados foram programados de maneira

a atender a diversas situações em que o robô se encontra.

6. PAUL, Christiane. Feedback: from object to process and system.

In: Feedback.

Gijón: LABoral Centro de Arte y Creación Industrial, 2007. inter-relacionados de forma sistêmica.

Neste híbrido, uma pequena "jiboia" (Epipremnum Pinnatum) é monitorada quanto à condutividade (resposta galvânica) em duas de suas folhas, que funcionam como sensores orgânicos para a orientação direcional de um robô. As variações eletrofisiológicas ocorridas nas folhas dessa planta são amplificadas e enviadas a um microcontrolador, que analisa os dados e ativa estados diferenciados na máquina5 ${ }^{5}$. São basicamente dois estados principais: repouso e interação planta-observador. Quando o sistema encontra-se em repouso, um sensor analisa a quantidade de luz ambiente e envia os dados para o microcontrolador, de maneira que o robô possa conduzir a planta até a fonte luminosa de maior intensidade. Ao se aproximar da luz o sistema entra em repouso. O segundo estado de máquina, que responde às interações com o observador, permite que o robô saia de sua situação de repouso e mova-se em direção ao estímulo. Isso ocorre quando o observador expira próximo a uma das folhas. $\mathrm{O}$ ato de expirar faz com que ocorram variações de condutividade na folha e uma diferença de potencial elétrico apareça no sistema. A partir desses dados o microcontrolador calcula os valores e aciona os motores do robô para levar a pequena planta em direção àquele que interage com o híbrido. Caso a interação cesse, o sistema volta a seu estado de repouso, buscando a luz e retornando o robô a seu local de origem. Esta estrutura básica, funcional e comportamental de Bot_anic nos servirá de ponto de apoio para as reflexões que seguem.

Figura 1 Bot_anic, 2013.

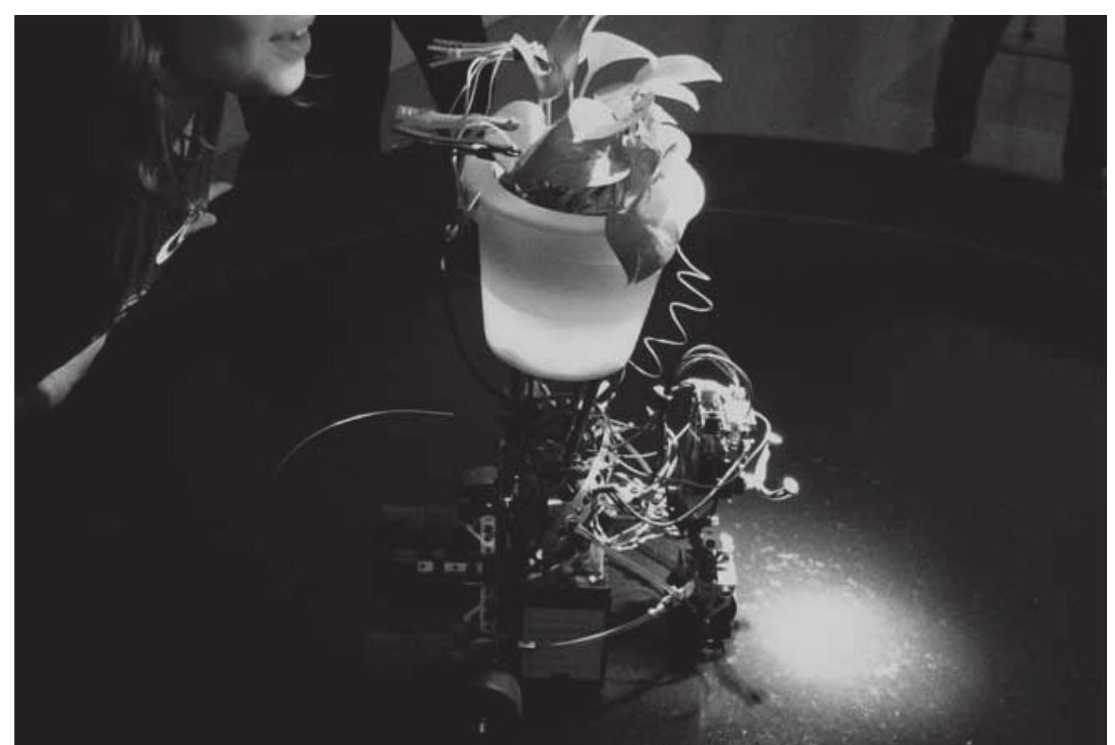


Considerando-se que a discussão aqui desenvolvida se dá no contexto da arte, nos cabe um primeiro questionamento: Qual o papel da criação de autômatos nos processos criativos das poéticas artísticas? Ou, de outra forma, que fator um sistema robótico poderá agregar à experiência sensível? Não se trata aqui de um simples retorno às perguntas seminais instauradas no momento em que, décadas atrás, se percebia os indícios de um crescente impacto das novas mídias, teorias da comunicação e sistemas computacionais sobre a sociedade. Como nos lembra Christiane Paul $^{6}$ nas décadas de 60 e 70 por meio de questões como: "qual o papel da arte numa sociedade tecnologicamente orientada? Estariam os computadores, eletrônicos de consumo e as teorias da comunicação transformando a produção de arte ou simplesmente a obscurecendo? Qual a relevância da tecnologia para arte, se há alguma, e estaria a arte operando sob um imperativo tecnológico?”. Questões que sinalizaram as primeiras especulações sobre o impacto que a técnica, a tecno-ciência e seu aparato maquínico viriam a exercer sobre a sociedade e a cultura.

Apesar de nos parecer que tais questões estejam longe de ter perdido o vigor, a discussão que ora se coloca decorre de uma perspectiva histórica avançada, na qual vemos, de certa forma, consolidada a transição de uma produção cultural "orientada a objetos" para outra "orientada a sistemas"7. Nesta nova cultura, nos diz Burham,

[m] udanças emanam não das coisas, mas da maneira como as coisas são feitas. (...) Sistemas têm seu ponto de vista focado na criação de constantes relações estáveis entre sistemas orgânicos e não orgânicos, sejam estes vizinhos, complexos industriais, fazendas, sistemas de transporte, centros de informação ou quaisquer outras matrizes da atividade humana ${ }^{8}$.

Diante deste novo paradigma, o foco das produções artísticas orientadas tecnologicamente, ou, poderíamos dizer, amparadas pelos recursos informacionais das tecnologias atuais, tem sido posto nos processos, naturais e artificiais, e nas infindáveis possibilidades de conectividade e organização de sistemas. O conceito de feedback - cuja importância para os sistemas de informação já fora apontada por Norbert Wiener em trabalho seminal que originou a ciência da cibernética ${ }^{9}$ - tem encontrado destaque especial na arte contemporânea, cujos processos interativos, derivados dos modos de participação e fruição de obras abertas, têm absorvido uma considerável atenção dos artistas. Na cibernética das interações, o composto artefato-
Bot_anic.

7. BURNHAM, Jack. Systems Esthetics (1968). Disponível em: <http://www.arts.ucsb. edu/faculty/jevbratt/ readings/burnham_ se.html. Acesso em: junho de 2008.

8. Ibidem.

9. WIENER, Norbert. Cybernetics: or control and communication in the animal and the machine. New York: M.I.T. Press. 1961.

10. Cf. ASCOTT, Roy. Op. cit.

11. ANDERSON, Chris. Makers - a nova revolução industrial. Elsevier - Campus, 2012. 
-artístico/observador se apresenta como um sistema auto-organizado, efetivamente homeostático na operação e controle de seus efeitos ${ }^{10}$. Como base no exposto, situamos nossa pergunta a respeito da construção de autômatos, dos sistemas auto-organizados, das hibridações entre modelos naturais e artificiais e seu papel como arte. Tal questão nos orienta ainda para uma reflexão sobre mais um fator característico de nosso tempo.

Vivemos, segundo algumas análises, das quais destacamos a do recente livro Makers, do editor da revista Wired, Chris Anderson ${ }^{11}$, uma nova revolução industrial instrumentada pelo poder das impressoras 3D, associadas ao efeito exponencial das redes de comunicação sobre a difusão, distribuição e interconexão de processos. Hoje cada indivíduo é potencialmente uma pequena fábrica motivada pelo conceito "faça você mesmo" (DIY - do it yourself). Inventar sistemas, produzir suas próprias máquinas e soluções processuais, tornaram-se não apenas possibilidades, mas uma tendência, alimentada por uma cultura que tem nas redes seu principal canal de acesso ao conhecimento e aos meios necessários para, com uso da tecnologia, não apenas reinventar o mundo, mas dispor sua nova invenção a uma sociedade interligada digitalmente. Segundo Chris Anderson a internet criou o contexto para que uma verdadeira transformação processual pudesse acontecer. Não mais dependemos totalmente das hierarquias de distribuição de conhecimento, dos parques tecnológicos, das fábricas e seus produtos. Cada indivíduo é um nó numa rede complexa que evolve suas interconexões. Mas de que maneira tal ideia impacta na arte?

\section{Transconectividade}

Figura 2 Breathing, 2009.

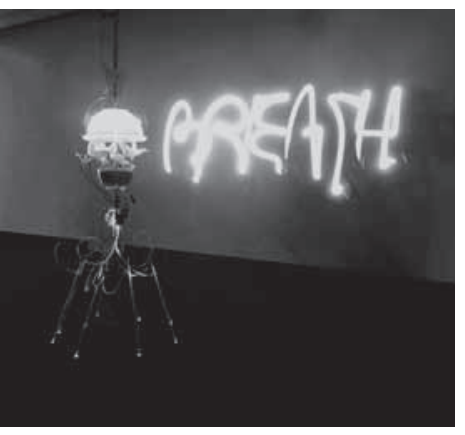

O gradual deslocamento do foco no objeto de arte para o conceito de sistema implicou num mergulho cada vez mais profundo nos processos, posto que os mesmos são determinantes no comportamento dos sistemas e seus estados. Portanto, os processos nos parecem ser força motriz a serviço da linguagem na arte. Contudo, com a efetiva penetração do dispositivo estético, pela aparelhagem técnica ${ }^{12}$, como já fora previsto por Walter Benjamin ${ }^{13}$, dispositvo este que agora é hiperativado pela capacidade conectiva das redes, e dado à ubiquidade dos sistemas de prototipagem rápida, nos vemos diante de um novo fenômeno. Tereza Cruz, em seu artigo "Da nova sensibilidade artificial" nos aponta que: 
O corpo estético aparelhado pela técnica entra numa nova relação à natureza, tornando evidente a crescente integração entre máquinas e organismos, mesmo nesse estrato complexo e aparentemente sem regras da experiência humana que é o da afecção ${ }^{14}$.

Essa integração, arriscaríamos dizer, indissociabilidade entre natureza e artifício, é que se vê catalisada pelas acelerações de um corpo técnico hiperlinkado e projetada no foco de atenção dos processos de constituição da experiência sensível. Não uma indissociabilidade que se quer forçada, pois, como mais uma vez nos antecipa Tereza Cruz:

Penetrado, e não substituído, pela aparelhagem técnica, o dispositivo estético torna-se então tão eficaz e tão efectivo na sua artificialidade, quanto a própria natureza. As novas máquinas da afecção tornam a sensibilidade artificial tão real quanto necessário para efectivamente sentir e padecer sem abandonar o seu torpor estético ${ }^{15}$.

É para tal relação de proximidade com a natureza e seus fenômenos sensíveis, ora hibridizados à técnica, que apontamos. Se os processos são parte inerente aos sistemas, e tendo estes sido amplificados e acelerados exponencialmente pelo avanço tecno-científico de nossa época, os dispositivos estéticos e o corpo maquínico decorrentes deste fazer apresentam aos artistas novas questões e desafios. Não basta engendrar processos, como não nos parece suficiente embarcar puramente no fetiche lúdico da criação de sistemas e máquinas, isso equivaleria a um retorno ao objeto, mesmo que este tenha adquirido uma roupagem cibernética e responsiva. Tais considerações nos permitem argumentar que a interatividade cede lugar no placo das atenções criativas, posto que a interação é fator inerente às mediações da técnica diante dos fenômenos e não o objeto de tais mediações. Para a construção de uma experiência sensível tecno-estética, entendemos ser necessário "a introdução, no sistema, de uma sensorialidade complexa, estimulável e reactiva, isto é, a sua transformação numa espécie de ecossistema tecnológico"16.

Através do raciocínio exposto chegamos a uma tentativa de resposta à questão lançada sobre a construção de máquinas/sistemas no contexto da arte. Se deslocarmos nossa atenção dos processos para o modo pelo qual os organismos engendrados no contexto da arte, sejam eles naturais ou artificiais, constituem uma espécie de ecossistema híbrido em sua natureza, notaremos que o grande desafio atual da sensibilidade artística é operar criativamente para a emancipação dessa rede sensorial complexa. Bot_anic, assim como tantos outros atores dessa rede, não se resume a um objeto estético, tanto quanto não se confina ou encaixa nos circuitos

\section{GUTO NÓBREGA}

Bot_anic.

12. CRUZ, Maria Teresa. Da nova sensibilidade artificial (2000).

Disponível em: <http:// bocc.ubi.pt/pag/cruzteresa-sensibilidadeartificial.html>. Acesso em: agosto de 2013.

13. BENJAMIN, Walter. A obra de arte na era da reprodutibilidade técnica. In: Magia e técnica, Arte e política. Ensaios sobre literatura e história da cultura. Obras escolhidas, v. 1. São Paulo, Brasiliense, 1994.

14. CRUZ, Maria Teresa. Op. cit.

15. Ibidem. 
tradicionais da arte. Deve ser pensado no contexto mais amplo de uma certa ecologia habitada por diversos outros agentes, nós incluídos - seres

16. Ibidem.

17. SIMONDON, G. On the mode of existence of technical objects. London: University of Western Ontario, 1980.

18. GESELL, Arnold Lucius. The embryology of behavior. Cambridge University Press. 1988 apud MERLEAU-PONTY,

Maurice. A natureza.

São Paulo: Martins

Fontes, 2000.

19. Ver conceito de conversação (conversation) em MATURANA, Humberto

R. Metadesign (1997).

Disponível em: <http:// www.inteco.cl/articulos/ metadesign.htm . Acesso em: outubro de 2008.

\section{Plantas e sistemas artificiais como arte}

Com o deslocamento de foco do objeto para o processo, investe-se, dessa maneira, em um mergulho temporal. Quebramos a magia da obra fechada e de um tempo cristalizado para nos arriscarmos nos devaneios da complexidade e da emergência. Vivemos o momento das conexões e da emancipação de organismos hiperconectados. Considerando-se processos que hibridizam sistemas naturais e artificiais, como no caso de Bot_anic, iremos notar, de forma ainda mais enfática, que se trata menos da construção de um produto final do que de uma amostragem contínua de pos- 
síveis entrelaçamentos entre natureza e artifício. O conceito de obra aqui poderia ser pensado como o de "organismo estético emergente" ${ }^{20}$, cuja duração se encontra condicionada ao tempo, espaço, ao meio em que se desenvolve, assim como sua fruição pelo público. Obra efêmera, atualizando-se a cada encontro, metabolizando-se no tempo. Quando plantas e máquinas são acopladas de forma híbrida para constituição de uma obra artística devemos pensar tal complexo como um sistema, e como tal, considerar a interação de suas diversas camadas significantes (subsistemas). Em Bot_anic plantas são incorporadas ao sistema levando-se em conta sua significação do ponto de vista popular, científico e pseudocientífico. São tais camadas conceituais, entrelaçadas de maneira sistêmica às funcionais, que criam ressonância na fruição do observador.

A experiência de Bot_anic coloca o observador em um lugar instável, que é o lugar criado pela arte. Este confronta um organismo que resulta de uma colagem sistêmica entre elementos naturais e artificiais, cujas camadas de significação se articulam sinergeticamente para prover ao observador uma experiência poética. A obra de arte pode ser assim pensada como um nó de informações através do qual o observador pode criar ressonância no artista através de uma interligação afectiva. A obra se vale do comportamento natural da planta, na maioria das vezes ignorados pelos nossos sentidos, e os projetam numa dimensão ampliada. Ao interagir com as folhas vegetais o participante dessa experiência não estará apenas ativando as funções automatizadas de uma máquina híbrida, mas, acima de tudo, gerando por meio de sua presença uma relação afectiva, que decorrerá de sua interconexão ao sistema. Com base nessa relação algumas questões podem ser reformuladas: De que forma os híbridos nos percebem e se transformam no contexto dessa nova ecologia? Como essa experiência afeta a nossa consciência sobre plantas, humanos, máquinas e o ambiente em que vivemos? Questões improváveis são amplificadas por esse sistema com o qual nos relacionamos numa experiência afectiva.

Mesmo não havendo respostas definitivas para tais questões, elas alimentam o campo da arte. Elas abrem o horizonte para novos diálogos com o mundo em que vivemos, dissolvendo antigas dicotomias, ao levar em consideração objetos técnicos não como uma ameaça contra a natureza, mas, de acordo com Gilbert Simondon, como possíveis "mediadores entre o homem e a natureza" ${ }^{21}$. A partir destes diálogos improváveis, contextualizados na experiência da arte, novas ecologias em curso têm sido mapeadas, assim como os homens e suas invenções avançado em direção a novos territórios.
GUTO NÓBREGA

Bot_anic.

20. NÓBREGA, C. Thinking hyperorganisms. Art, technology, coherence, connectedness, and the integrative field. Saarbrücken: LAP Lambert Academic Publishing, 2010. 


\section{Conclusão}

ano 11

n. 22

21. SIMONDON, Gilbert. Op. cit., p. 1.

Vivemos outros tempos, novas agendas e dinâmicas. Não devemos pensar a arte ancorados em paradigmas históricos, mas adotar critérios e estratégias fluidas, capazes de responder aos anseios de nosso momento e suas potências mais legítimas. Acreditamos que cabe tanto ao artista quanto ao fruidor da obra, seja este o público ou o crítico, lançar um novo olhar sobre tais experimentações. Elas refletem um mergulho em estruturas vivas, reinventam a natureza e geram novas redes. Se pensarmos a arte como um organismo, veremos que uma boa estratégia criativa é buscar respeitar e entender sua própria natureza mutante.

Carlos Augusto Moreira da Nóbrega (Guto Nóbregal é professor da Escola de Belas Artes - Universidade Federal do Rio de Janeiro (UFRJ) e membro do NANO - Núcleo de Artes e Novos Organismos.

Figura 4 Breathing, 2009.

Artigo recebido em 28 de outubro de 2013 e aprovado em 18 novembro de 2013.

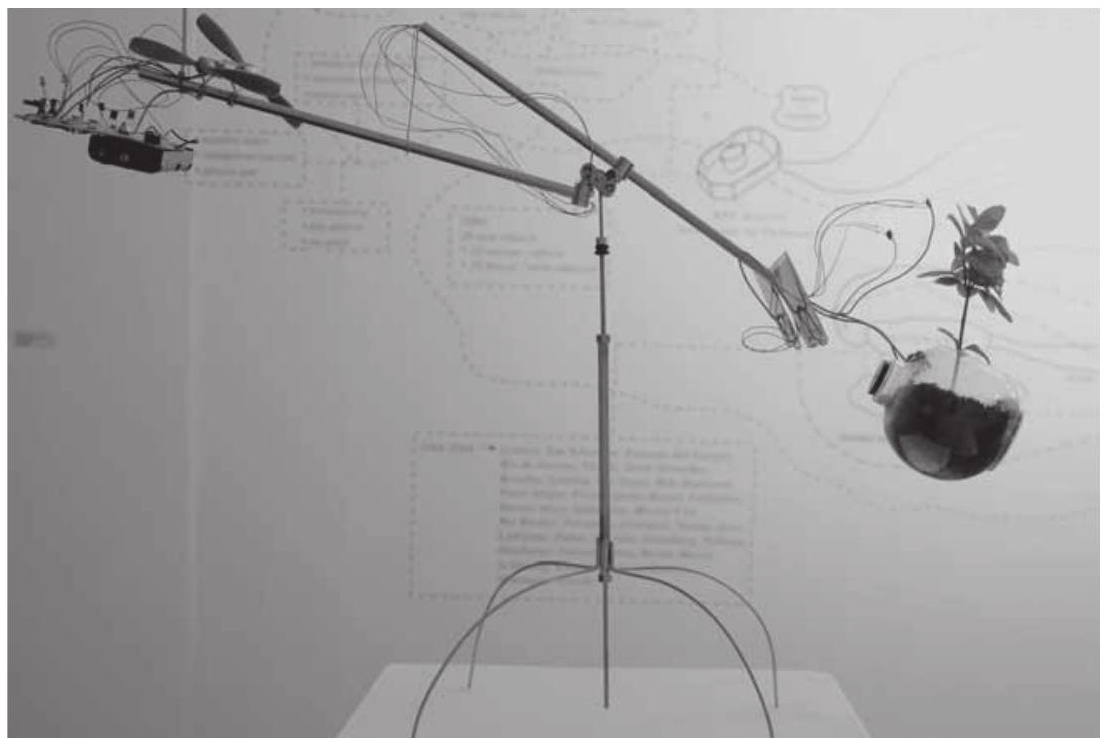

